\title{
The use of interactive media in foreign language learning
}

\author{
Peter Olaf Looms \\ DRIVE \\ Danmarks Radio (the Danish Broadcasting Corporation)
}

\begin{abstract}
This paper discusses the use of interactive videodiscs and CD-ROMs in connection with the learning of foreign languages in Denmark and selected countries (Australia, France, the Netherlands, the United Kingdom and the USA). Discs currently being used include specially produced language discs, authentic materials (films and documentaries), multimedia databases and discs originally developed outside Denmark for use in subjects other than languages. The hardware required ranges from a monitor, simple LaserVision player and remote control to computer-based systems with one or two screens. Many of the materials in use or under development suffer from the fact that they are designed for use by individuals on hardware configurations costing between US $\$ 4,000$ - $\$ 10,000$. The paper includes suggestions for external funding and potential partners for EC applications, as well as a listing of institutions currently working in the field.
\end{abstract}

The earliest reported use of videodiscs in the teaching of languages dates back to 1979. Larrie E. Gale and his colleagues at Brigham Young University in Utah, USA transferred a Mexican film entitled Macario to videodisc to enable students to improve their listening comprehension and to analyse the plot. Later that year work began on Montevidisco, a computer-controlled videodisc allowing students to simulate a visit to a small Mexican village. Users were offered choices as to where they wanted to go, and were expected to answer questions put by local inhabitants.

Work on the interactive use of optical discs has concentrated on listening comprehension and speech, with reading and writing being given a lower priority. Exceptions include the remedial language learning package PALS (Principles of the Adult Literacy System) from IBM in the USA, which is designed to develop the reading and writing skills of adolescents and 
adults; Writing for Results, a course for American adults; and recent interactive fiction such as Amanda, a Macintosh programme on CD-ROM for preschoolers.

\section{Videodiscs specially made for language teaching}

Public broadcasting systems in Europe later funded experimental discs based on footage from television courses, usually requiring a microcomputer. Among the titles developed were Des Le Debut, Ensemble, Kontakte, Flight 505, Bid for Power and iDigame! (developed by institutions such as Brighten Polytechnic, UK and Brigham Young University, USA for different departments of the BBC). From 1983 a limited number of LaserVision discs were made available for sale to the general public such as Ensemble, Kontakte, (BBC Enterprises), Avec Plaisir (Hachette), and Switch on English (Klett Verlag, Federal Republic of Germany). Many were designed for use without a computer.

Since 1986, developments have taken a new turn, and videodiscs have been developed specifically for interactive use.

In the UK significant projects include French and German materials at Lancashire Polytechnic, Expodisc Spanish, (The Buckinghamshire College), The European Connection (BBC English by Television, Brighten Polytechnic, Lancashire Polytechnic and sponsored by IBM), and a schools disc, Siville (Shropshire, England), produced as part of the Interactive Video in Schools programme.

In the USA, Larrie Gale's team at Brigham Young University in Utah has produced an English course for Japanese businessmen (Flight 505) and an interactive version of the BBC television course Digame! for use in classrooms. The Interactive Video Language Lab, IVLL, (University of Massachusetts, Boston, USA), has produced a series of titles in a variety of languages, as has Project Athena (MIT, Boston, USA). The US Armed Forces have been responsible for producing a series of discs, primarily to prepare staff for service overseas, one of which is Velvet. Publishers have shown renewed interest in the field in 1989, with the appearance of Diez Temas and Quinze Minute from the Encyclopaedia Britannica Education Corp. and German Language and Culture from Calico filmed on location near Heidelberg. Interactive Training Inc. has followed up the PALS project with SKILLPAC - English for Industry, a course for native speakers and immigrants. A similar material is The Safe Affair from the University of Michigan at Ann Arbor which is based on a courtroom drama simulation of an alleged theft of a large sum of money from a travel agency safe. In the area of language and area studies, discs in less commonly taught languages such as Japanese are now been marketed. 
One project meriting special mention was produced by the Adelaide College of Technical and Further Education in Australia. A team comprising Herb Peppard, Tony Schick and Nigel Russell (now working independently) produced a disc for both class and individual use, The Aussie Barbie, for teaching English to immigrants in Australia. This disc is now in use in English as a Foreign Language programs in Denmark and Norway, and its dual design as both a computer-controlled and a "computerless" disc lends itself well to language classes concerned with the language and its social context. The team is now working on further languages discs.

Paris en Video (ECC, Holland) was published several years ago, and uses HyperCard as the basis of a two-screen configuration.

In Denmark, a pilot project based on a film about Edith Piaf was developed by Torsten Alf Tensen with funds from CPI and was used with some success at the Christianshavn upper secondary school in Copenhagen. Eva Dam Jensen and her colleagues at the Institute for Romance Languages at the University of Copenhagen have expanded their work with El Camello, an outstanding video course in Spanish, and have produced an intermediate course for use on videodiscs entitled Encuentros (University of Copenhagen, Denmark). In September 1989 work began on a language course for the Fredericia Breweries. The partners in this project are Fredericia Uddannelsescenter (Torsten Alf Jensen, Cathy Toscan), staff at the Copenhagen School of Economics \& Business Administration (Vibeke Rechnitzer) and the University of Copenhagen (Karen Landschultz). The work on this project is funded in part by Law 271 on Continuing Education in Denmark. An English language project is also under way with Law 271 funding: Slagelse Technical School and engineering consultants Birch \& Krogboe are the main partners.

Most of these projects run on one of a number of common configurations. In a European context, the most common for generic language courses for commerce and industry is based on the Video Logic IVA 2000 or 3000 genlock card for the IBM AT or compatibles, and the Video Logic IVA 4000 card for the PS / 2 series. Several developers are also using bar codes to control videodiscs for use in group and class work.

In the USA, common configurations include IBM's InfoWindows and twoscreen configurations based on a Macintosh and Pioneer or Sony videodisc player, built around HyperCard.

\section{Repurposing films and documentaries on videodisc}

Developments since 1986 have followed different routes: some educational institutions have developed interactive materials based on films such as Raiders of the Lost Ark (USA) or Edit Piaf (Denmark), and Out of Battle 
(Denmark), requiring computer control. Consumer discs designed for nonlinear use such as Murder Anybody? have been used but with limited success. One centre in Denmark, AAIC, (Arhus Amts Informatikcenter), has concentrated on this approach, and has developed authoring software to exploit consumer discs (CLV) of this kind in the classroom. In the USA, commercial products based on this approach are now available, for instance Teaching English Through Film: Citizen Kane from Edudisc Inc. The Odense Technical School in Denmark has also supported authoring software for language teachers.

\section{Repurposing existing interactive materials for language learning}

Another route followed by language teachers in Denmark is the repurposing of existing materials for other subjects from the UK and France for use as a resource in the language classroom. Materials such as Moi, Mon Metier (Poitiers, France), The Domesday Project, Volcanoes and The EcoDisc (BBC Enterprises), Frame Up!, a simulation programme from Imedia developed for the French Ministry of Education, and The North Polar Expedition (Interactive Virgin, England) are all currently in use by 11 to 18-year-olds in Danish schools. In such materials, the materials are designed to be used by groups, and roles are assigned to individuals or to pairs.

Negotiations are in progress to use discs such as Ask the Workers..., a videodisc package designed for use in careers counselling in Australia but with potential in Scandinavian schools for the teaching of English and area studies.

With the advent of multilingual CD-ROMs such as the EcoDisc (an Apple Macintosh CD-ROM released originally in April 1989 with text and sound in nine languages), experience has also been gained in the use of such materials in interdisciplinary studies (languages and biology). Mogens Herirup at Rising School in Odense has published a paper on their experience in this field.

In the field of languages for commerce and industry, there would seem to be considerable scope for repurposing existing in-service training discs for language in areas such as safety (four titles available on the InfoWindows configuration) and business (over fifty generic titles are available).

Projects at technical schools in Odense, Horsens and Arhus, and the INTERCOM group, which comprises teachers from further education and Esbjerg Technical School, involve the modification of existing disc-based materials. 


\section{Low-cost solutions using bar codes}

Since 1988, institutions such as DRIVE, four local authorities and Waves Information Technology in Denmark, and IMA and the Stavanger Teacher Training College in Norway have worked on low-cost applications using bar codes to control a LaserVision player without a computer. These materials make use of off-the-shelf discs such as Paris en Video or experimental discs such as Bid for Power. Using a bar code reader, the user can access a given sequence on a videodisc almost instantly, repeat that sequence with or without sound or image, or freeze the image for as long as required. Bar codes will be expanded to enable users to control compact discs and CD-ROMs at a later stage.

WAVES has recently developed a universal bar code reader which can be used with all industrial videodisc players with an RS 232C port. The system uses the interleaved 2 of 5 bar code standard published by Pioneer and Sony in 1988. In the UK the Visual Answers company has developed a proprietary bar code standard, and one of the two is likely to be chosen for use in a forthcoming schools project funded by the Department of Education and Science in the UK

\section{Hardware for interactive video in foreign language learning}

It is convenient to distinguish between interactive video used for individual study at school or home and interactive video designed for use in the classroom by groups or the whole class.

Most of the projects mentioned above have been designed for use by individuals, and typically require a computer with genlock card, LaserVision player and a television monitor costing typically $\$ 4,000$ to $\$ 10,000$. There are seldom more than two or three titles available for a given configuration, the major problem being the type of computer and the genlock card used. Marketing a new interactive language disc or discs is therefore a hazardous matter, as two or more configurations may need to be considered.

At present, the most widely used configuration in Danish technical schools and industry is based on the VideoLogic IVA 3000 card with an IBM compatible computer and a Philips, Pioneer or SONY player. This system costs of the order of $\$ 7,000-\$ 8,000(\mathrm{Kr} 50,000)$.

In the CD-ROM field, the Macintosh offers an integrated environment including sound, and a number of multilingual projects in the field of technical manuals are being developed for this platform. Putting together an IBM equivalent would cost the same and not have the advantages of built-in compatibility. The main drawback to date is the sluggish access to digital audio. 
An alternative is to build on experience from Brigham Young, DRIVE and the University of Copenhagen concerning low-cost solutions for individual and classroom use. A solution comprising a LaserVision player and bar code reader costs as little as $\$ 1,000$ (USA) to $\$ 1,200$ (Europe), and can be used with an existing television set. Bar code readers are now available which can be used with all available LaserVision players, so that standards no longer represent a significant problem.

Another low-cost solution currently under development is that of Compact Disc Interactive (CD-I). CD-I is a further development of Compact Disc technology aimed at the "edutainment" market. The disc allows for the delivery of text, stills, sound in four qualities and full motion video in a window and employs a 68000 series processor running under RT-OS (a derivative of the OS 9 operating system). Currently units are available for professional use at a price of $\mathrm{Kr} 25,000$ but units are likely to be available for less than $\mathrm{Kr} 10,000$ within three years. New Media in London are currently working on a CD-I in Japanese for businessmen for release in late 1990. If the format is successful on the consumer market, it will be the format of the nineties.

Digital Video Interactive (DVI) represents an alternative, PC-based approach to CD-I. DVI plans to offer the same capabilities as CD-I by 1992 and offers an evolutionary path from CD-ROM via CD-ROM Extended Architecture CD-ROM/XA to DVI.

Both CD-I and DVI hold the promise of very low duplication costs for mass distribution (typically US $\$ 3$ per disc) but suffer from very high initial development costs and the lack of proven authoring and premastering environments. Delivering full-motion video with VHS quality will not be a reality until 1992 and broadcast quality until 1994 at the earliest. For the next three to five years video of adequate quality will require specialised image compression services at one of three sites around the world.

\section{Sources of external funding and potential partners in the EC}

Among potential sources of funding are the LINGUA and the SPRINT programmes of the CEC. DRIVE is working with the BBC Interactive Television Unit and organisations in Portugal and Spain on a forum for the production of interactive multimedia for basic language learning using material from public broadcasting. The aim is to ensure the production of interactive media on a commercial basis in a limited number of target languages but taking into consideration at least nine different mother tongues.

Several consortia applied unsuccessfully for the European Economic Community DELTA II programme funding for language projects. Among potential partners in the EC are: 
- UK

- Brighten Polytechnic

- Lancashire Polytechnic

- BBC ITU

- BBC English by Television, now called the Multi Media Company

- Exeter College of Education

- National Centre for Computer Aided Language Learning (Ealing College pie)

- Next Technology, Cambridge (Peter Bratt joined the staff in January 1990)

- Norway

- NAVF's senter for humanistisk edb, Bergen, Norway

- Denmark

- Waves Information Technology, Copenhagen, Denmark

- Romansk Institut, Copenhagen, Denmark

- Odense Technical School, Denmark

- Holland

- NIAM

\section{Selected contacts:}

Aussie Vision Pty. Ltd.

Nigel Russell

PO Box 229, Kensington Park

South Australia

5068 fax (08)3324647

Brigham Young University

Larrie E. Gale

E-509 HFAC, Provo

Utah UT 84602 USA

tel. +18013787082

Brighten Polytechnic

Cathy Watts

The Language Centre

Falmer, Brighton BN1 9PH

fax : +44 273690710

The Buckinghamshire College

Paul Bangs

Manager, EXPODISC

Queen Alexandra Road

High Wycombe, Bucks HPII 2JZ

ENGLAND

fax: +44 49424392
Fredericia Uddannelsescenter

TorstenAlf Jensen/Cathy Toscan

Informationsprojektet Interaktive Medier

Mosegadsvej 2

7000 Fredericia

fax: +4475940488

IMA Associates

Aske Dam

Fossekleiva

N-3075 Berger i Vestfold

NORWAYtel: +473775580

The Interactive Language Learning

Laboratory

Carla Meskill

University of Massachusetts

Harbor Campus

MA 02125 Boston USA

tel: $+16179297325 / 8349$ 
Lancashire Polytechnic

The Interactive Learning Unit

37 St. Peter's Street

Preston PR 1 7BS

Lancashire

ENGLAND

tel +44 772201406

Monitor Information Systems Ltd

17 Toxteth Road

Glebe, Sydney

Australia 2037

fax (02)5522140

Stavanger Laererhogskole

Dan Dyrli Daatland

Boks 2521 Ullandhauge

N-4004, Stavanger

\section{NORGE}

tel: +474558600

Virgin Interactive Video

Virgin Publishing Ltd

The Hon. William Beckett

General Manager

2-4 Vernon Yard

119 Portobello Road

London W11 2DX

ENGLAND

fax : +44 17278965

Waves Information Technology ApS

Jorgen Schultz

Forskerbyen Symbion

Haraldsgade 68

2300 Copenhagen

fax : +4431817833

Author: Peter Olaf Looms can be contacted at: The Danish Broadcasting Corporation

DRIVE

Islands Brygge $81 \mathrm{DK}-2300$ Copenhagen $S$

tel. +4531671233 extension $6884 / 6885$ fax. +4531953110

Please cite as: Looms, P. O. (1990). The use of interactive media in foreign language learning. Australian Journal of Educational Technology, 6(1), 11-19. http: / / www.ascilite.org.au/ ajet/ ajet6/looms.html 